\title{
Article \\ Efficacy of a Modified Clinoptilolite Based Adsorbent in Reducing Detrimental Effects of Ochratoxin A in Laying Hens
}

\author{
Marko Vasiljević ${ }^{1}$, Darko Marinković ${ }^{2}$, Dragan Milićević ${ }^{3}{ }^{\circledR}$, Jelka Pleadin ${ }^{4} \oplus$, Srđan Stefanović ${ }^{3}$, \\ Saša Trialović ${ }^{5}$, Jog Raj ${ }^{6}$, Branko Petrujkić ${ }^{7}$ and Jelena Nedejković Trialović ${ }^{7, *}$ \\ 1 The Faculty of Veterinary Medicine, University of Belgrade, Bulevar oslobodjenja 18, 11000 Belgrade, Serbia; \\ marko.vasiljevic@patent-co.com \\ 2 Department of Pathology, Faculty of Veterinary Medicine, University of Belgrade, Bulevar oslobodjenja 18, \\ 11000 Belgrade, Serbia; darko@vet.bg.ac.rs \\ 3 Institute of Meat Hygiene and Technology, Kaćanskog 13, 11040 Belgrade, Serbia; \\ dragan.milicevic@inmes.rs (D.M.); srdjan.stefanovic@inmes.rs (S.S.) \\ 4 Croatian Veterinary Institute, Laboratory for Analytical Chemistry, Savska cesta 143, 10000 Zagreb, Croatia; \\ pleadin@veinst.hr \\ 5 Department of Pharmacology and Toxicology, Faculty of Veterinary Medicine, University of Belgrade, \\ Bulevar oslobodjenja 18, 11000 Belgrade, Serbia; sasa@vet.bg.ac.rs \\ 6 Patent Co, DOO., Vlade Ćetkovića 1A, 24211 Mišićevo, Serbia; jog.raj@patent-co.com \\ 7 Department of Animal Nutrition and Botany, Faculty of Veterinary Medicine, University of Belgrade, \\ Bulevar oslobodjenja 18, 11000 Belgrade, Serbia; petrujkic@vet.bg.ac.rs \\ * Correspondence: tjelena@vet.bg.ac.rs
}

check for updates

Citation: Vasiljević, M.; Marinković, D.; Milićević, D.; Pleadin, J.; Stefanović, S.; Trialović, S.; Raj, J.; Petrujkić, B.; Trialović, J.N. Efficacy of a Modified Clinoptilolite Based Adsorbent in Reducing Detrimental Effects of Ochratoxin A in Laying Hens. Toxins 2021, 13, 469. https:// doi.org/10.3390/toxins13070469

Received: 31 May 2021

Accepted: 1 July 2021

Published: 7 July 2021

Publisher's Note: MDPI stays neutral with regard to jurisdictional claims in published maps and institutional affiliations.

Copyright: (c) 2021 by the authors. Licensee MDPI, Basel, Switzerland. This article is an open access article distributed under the terms and conditions of the Creative Commons Attribution (CC BY) license (https:// creativecommons.org/licenses/by/ $4.0 /)$.

\begin{abstract}
Background: The objective of this study was to evaluate the efficacy of modified clinoptilolite (Minazel Plus ${ }^{\circledR}, \mathrm{MZ}$ ) as a mycotoxin adsorbent for preventing the negative the effects of ochratoxin A (OTA) on performance, pathohistological changes, and OTA residue in the eggs of laying hens. Methods: Forty eight $(n=48)$ laying hens ( 27 weeks old) were equally divided into six groups and depending on the type of addition were allocated to the following experimental treatments for 7 weeks: E-I group-1 mg/kg OTA; E-II group $0.25 \mathrm{mg} / \mathrm{kg}$ OTA; E-III group $1 \mathrm{mg} / \mathrm{kg}$ OTA $+0.2 \%$ of MZ; E-IV group $0.25 \mathrm{mg} / \mathrm{kg}$ OTA $+0.2 \%$ of MZ; MZ group supplemented with $0.2 \%$ of the adsorbent; and control ( $\mathrm{K}$, without feed additive). Results: Overall, the addition of $0.2 \% \mathrm{MZ}$ to laying hen feed mitigated the harmful effects of OTA on target organs and reduced the presence of OTA residue in eggs. The groups that received $0.2 \%$ of $\mathrm{MZ}$ achieved better production results in terms of body weight, number of eggs, and feed consumption, compared to the other treatments. Conclusions: The current findings confirm the efficacy of $\mathrm{MZ}$ in preventing performance losses in laying hens exposed to OTA, as well as for improving the welfare and health of food producing animals.
\end{abstract}

Keywords: adsorbent; OTA; performance traits; pathohistological changes; OTA residue; eggs; risk assessment

Key Contribution: Feeding of OTA at $1 \mathrm{mg} / \mathrm{kg}$ decreased the production performance of laying hens, produced histopathological alterations in the liver and kidney, and effected the presence of OTA residue in eggs. The addition of modified clinoptilolite (Minazel Plus ${ }^{\circledR}, \mathrm{MZ}, 0.2 \%$ ) as a mycotoxin adsorbent can counteract the deleterious effects caused by OTA.

\section{Introduction}

Mycotoxins are products of the secondary metabolism of certain filamentous fungi. These fungal species, when present in food and feed in sufficiently high levels, may cause serious diseases in animals and humans. Of the thousands of mycotoxins, OTA is one of the best known, and with the greatest public health and agro-economic significance due to its worldwide occurrence and prevalence [1]. OTA is primarily produced during storage 
by several fungal strains of Aspergillus and Penicillium species under varying environmental conditions (in tropical, warmer, or colder regions) [2]. OTA is considered a potent nephrotoxic mycotoxin that causes renal toxicity and possesses carcinogenic, teratogenic, immunotoxic, and possibly neurotoxic properties, based on experimental animal studies [1]. Thus, OTA has been classified by the IARC as a possible human carcinogen (Group 2B) [3].

In animals, mycotoxins produce a broad range of harmful effects on livestock health, production, and welfare, resulting in significant economic losses [4]. Mycotoxins cause economic losses, either directly due to animal's death, or indirectly due to reduction in animal productivity, increased incidence of disease due to immuno-suppression, damage to vital organs accompanied by pathological change, interference with reproductive performance, and reduced or no response to veterinary therapies [5]. In poultry, after a prolonged OTA intake at a level of $0.5 \mathrm{mg}$ OTA $/ \mathrm{kg}$ in feed, signs of chronic ochratoxicosis linked to renal diseases occur, followed by a decrease in feed intake and disorders in egg production and egg quality [6]. It is important to emphasize that in field conditions non-specific signs of mycotoxicosis associated with the presence of multiple contributing factors occur, making it difficult to establish a clinical diagnosis. OTA has the potential to bioaccumulate in the organism, and thus consumption of OTA by birds may also be associated with the appearance of OTA residues in edible tissues and eggs [7,8], which might affect the safety of egg production throughout the food chain. Among food commodities, little is known about the risks posed by exposure to mycotoxins by consuming poultry products in Serbia [9].

In temperate countries such as Serbia, OTA is produced by P. verrucosum, which has been found to be associated with contamination of several foods and feedstuffs. Thus, OTA is one of the most studied mycotoxins in this region. Recently studies have confirmed that prolonged drought favored the growth of certain Aspergillus species and synthesis of OTA [10]. Extreme weather events in Serbia pose one of the greatest risks for the contamination of cereals such as wheat, maize, barley, and oat by various species of ochratoxigenic fungi and their related metabolites [11]. Milicevic et al. [12] suggested a set of prevention and control measures to mitigate the negative effects of mycotoxins on animal health, quality, and the safety of their products. In intensive poultry production various mineral adsorbents are often used to mitigate the harmful effects of mycotoxins $[13,14]$. Minazel Plus ${ }^{\circledR}(\mathrm{MZ})$ is an adsorbent created as a result of an ion exchange reaction between inorganic cations on the mineral surface and organic cations. The addition of organic cations is used to change the mineral surface. The result of this addition is not a simple mixture of mineral and organic phases, but a completely new compound that is an organic complex. New active centers, which are formed on the mineral surface, ensure efficient binding, not only of polar mycotoxins (Aflatoxins, Ergot Alkaloids, etc.), but also of nonpolar mycotoxins (Zearalenone, Ochratoxin A, T-2 toxin, etc.).

The aim of this study was to assess the effect of a locally available, low-cost, and patented modified clinoptilolite adsorbent (MZ) for reducing the adverse effects on growth performance and target tissues, as well as on egg quality parameters and OTA residues in the eggs of laying hens fed with OTA-contaminated feed. In addition to determine the protective effects of the adsorbent, the presence of OTA residues in eggs during the in vivo experimental trial was evaluated, with a hypothetical estimation of human daily intake (EDI) of OTA by consuming eggs contaminated with OTA. The results of our study are expected to raise awareness of the health risks associated with the presence of OTA in the feed of laying hens.

\section{Results and Discussion}

\subsection{The Effect of Modified Clinoptilolite on Performance of Laying Hens}

The effects of modified clinoptilolite (MZ) on the performance of laying hens were separately analyzed, and the results of the analyses are presented in Figures 1-3. In this study, OTA decreased the body weight compared to the control and MZ groups (Figure 1). 


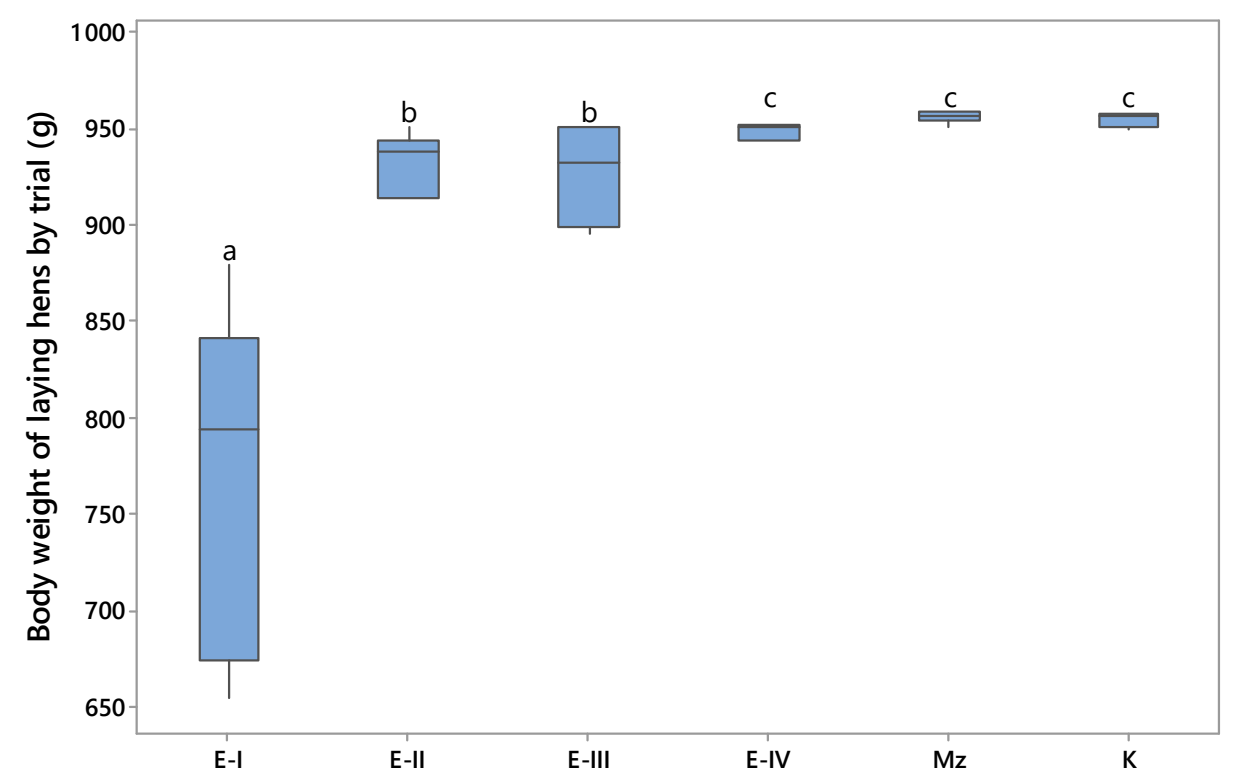

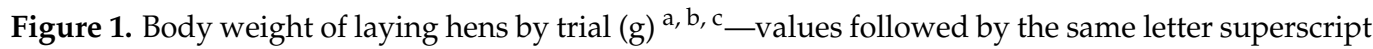
are not different at $p<0.05$ (according to Tukey's method).

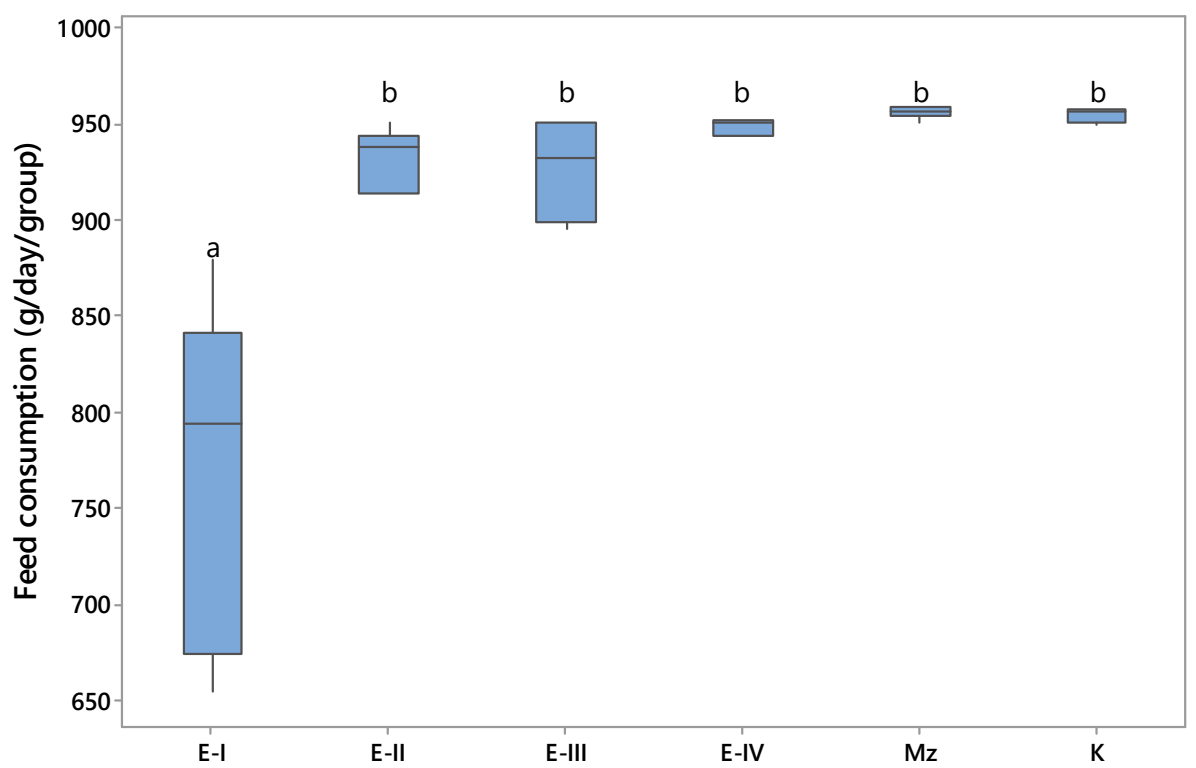

Figure 2. Feed consumption (g/day/per group) ${ }^{a}$, b - values followed by the same letter superscript are not different at $p<0.05$ (according to Tukey's method).

At the beginning of the study there was no difference in the average body weight between the treated and control hens. However, during the experiment, particularly from the second week, the body weight of hens in the E-I group tended to be lower $(p<0.05)$ in comparison to all other experimental and control groups. A decrease in body weight associated with a decrease in daily feed consumption was recorded in the E-I group (Figure 2). This result is in agreement with that of Elaroussi et al., 2006 [15], who reported that OTA-associated decreased body weight gain is not caused by the direct effect of OTA, rather is related to reduced feed intake. It is clear that birds from the E-I group might have shown clinical signs of ochratoxicosis. Furthermore, it must also be taken into account that the nutrient absorption capacity of the gastrointestinal tract is probably reduced in these groups. The addition of MZ in the OTA-containing diets (E-III and E-IV) significantly $(p<0.05)$ ameliorated the adverse effects of OTA on body weight. Moreover, body weight 
in group E-III was $20.72 \%$ higher as compared to the control, group E-I. The current findings were similar to the findings of previous researchers, where mineral adsorbent added to diets contaminated with OTA improved the performance of laying hens $[14,16,17]$.

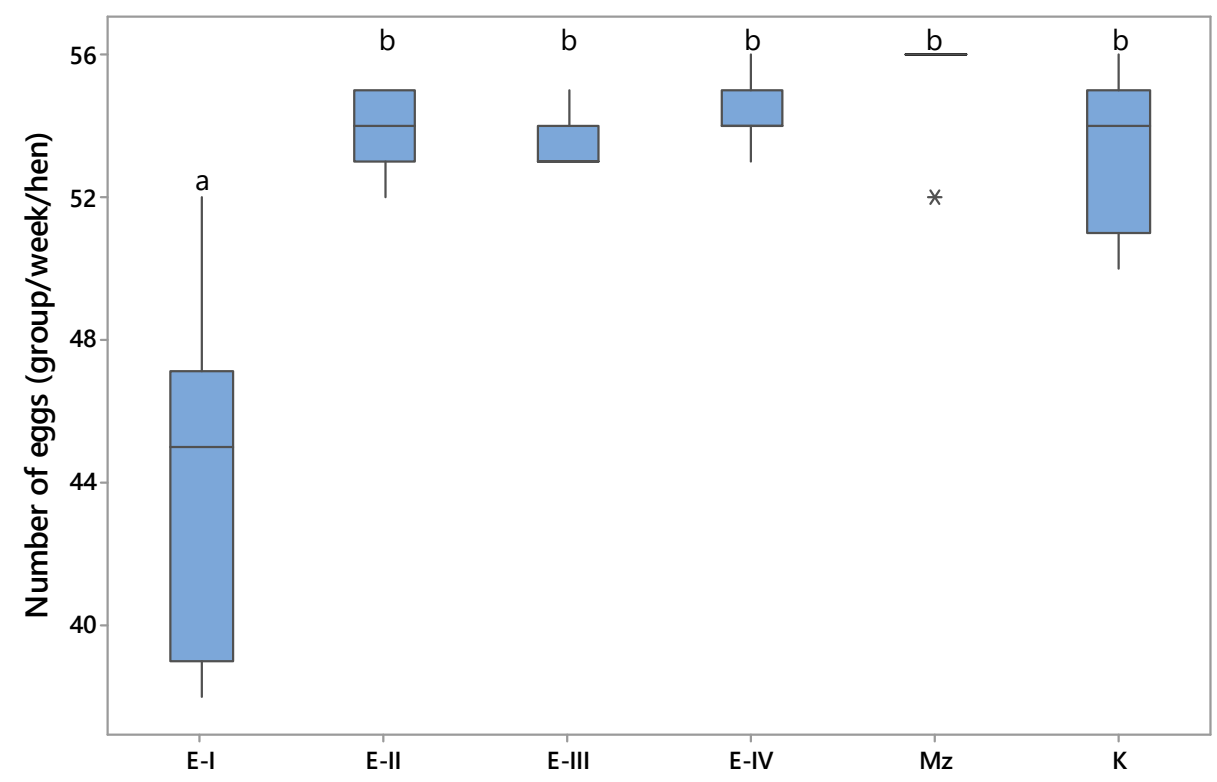

Figure 3. Number of eggs, group/week/hen ${ }^{a, b}$ — values followed by the same letter superscript are not different at $p<0.05$ (according to Tukey's method). Asterisk $\left(^{*}\right)$ identified the outliers which are observed at least 1.5 times of the interquartile range (Q3-Q1) from the edge of the boxplots.

The results presented in Figure 2 show that similar results were observed with the consumption of feed. Compared to all experimental groups and the control group, feed consumption was significantly lower $(p<0.05)$ in the hens fed $1 \mathrm{mg} / \mathrm{kg}$ of OTA in their diet (E-I), whereas no significant differences were observed between the control and MZtreated groups. In this case adding $0.2 \%$ of $\mathrm{MZ}$ to the feed for laying hens (E-III) had a positive impact on feed consumption (13.5\%). This finding is in agreement with the results of several previous studies, which observed that exposing birds to OTA, with minimal amounts of OTA $(>0.5 \mathrm{ppm})$, caused a negative effect on the broiler performance [6]. Although, throughout the study, the hens of the E-II group, which were given the diet with $0.25 \mathrm{mg} / \mathrm{kg}$ OTA, had periodically lower feed consumption, no statistically significant differences in the feed consumption were observed among groups that received OTA without (E-II) and with (E-III and E-IV) supplemented MZ.

The effects of OTA-contaminated diet on average weekly egg production of laying hens over the 49-day period are shown in Figure 3. The present study shows that the daily egg production was significantly reduced $(p<0.05)$ in group E-I, fed with $1 \mathrm{mg} / \mathrm{kg}$ of OTA. These negative results persisted throughout the entire experiment. The results of the current experiment suggest that MZ supplementation is required under such circumstances. In this study, OTA at a level of $0.25 \mathrm{mg} / \mathrm{kg}$ did not influence egg production. The highest number of eggs was produced by hens which received the commercial diet containing $0.2 \% \mathrm{MZ}$. However, there were no statistically significant differences $(p>0.05)$ between the experimental treatments and the control group regarding the number of eggs.

Taken together the current findings imply that the presence of OTA at dietary concentrations of $0.25 \mu \mathrm{g} / \mathrm{kg}$ (E-II) did not influence body weight, feed consumption, or the number of eggs of laying hens. It is necessary to point out that this level is higher than the Serbian regulatory limits for OTA in feed $(0.20 \mathrm{mg} / \mathrm{kg})$ for laying hen diets [18] or the EU maximum recommended concentration of $0.1 \mathrm{mg}$ OTA $/ \mathrm{kg}$ in poultry feed [19]. Results of the current experiment mostly agree with the findings from other studies, where exposure to OTA in low or moderately contaminated feeds did not markedly affect growth performance in poultry [20]. In contrast, the presence of OTA at the concentration of $1 \mathrm{mg} / \mathrm{kg}$ 
in the ingested feed negatively affected laying hen productive performance. It is well known that OTA in ingested feed negatively affects the microvilli of the intestine, including increasing gut permeability, immunity, and bacterial translocation, thereby reducing nutrient absorption [21]. Overall, during the entire experiment, the addition of $M Z$ as a feed additive effectively ameliorated the negative effect of OTA and had significant beneficial effects on body weight, feed consumption, and the number of eggs of laying hens.

The data reported in this study were similar to those obtained by several other authors $[2,14,16,22]$, which confirms that exposure to OTA contaminated feed for a longer period causes a significant decrease in poultry production. Since the gastro-intestinal epithelium is the first barrier meeting mycotoxins, the adverse effect of mycotoxins on the intestinal integrity can be counteracted by the addition of a mycotoxin absorbent. Thus, mycotoxin adsorbents exert an influence on gastro-intestinal health, which can affect nutrient digestibility and therefore improve animal performance and health. The use of clinoptiloite as an absorbent has been extensively studied in Serbia $[13,23,24]$. Despite other studies that have shown clinoptilolite to be not effective for all mycotoxins or that it might have a negative influence on performance, the present study suggests that clinoptilolite supplementation in poultry feed at the level of $0.2 \%$ led to a significant reduction of the harmful effects of OTA, as well as an increase in feed consumption, body weight, and the number of eggs of laying hens.

\subsection{The Effect of Modified Clinoptilolite on Macroscopic and Pathomorphological Alterations in Target Organs}

The level and duration of exposure are the main predisposing factors regarding the severity of alterations and adverse effects of mycotoxins on poultry health and productivity. The kidney appears to be the primary target organ for OTA toxicity $[7,25]$. Macroscopic examination showed noticeably enlarged kidneys and livers in hens treated with different amounts of OTA, with a paler color than in other groups. Histopathological examination of kidneys revealed degenerative changes to tubulocytes (cloudy and hydropic degeneration), together with necrobiotic changes (karyopyknosis, karyorrhexis, karyolysis) (Figures 4 and 5). Moreover, tubular atrophy (Figure 6) and cystic dilatation of the tubular lumen and vascular changes (vascular oedema) were observed. All mentioned changes in the kidneys were mainly seen in hens treated only with OTA, while less pronounced but also notable changes were observed in laying hens which had, in addition to OTA in feed, received the adsorbent (Figure 4). Such pathomorphological alterations have also been reported in several studies where the OTA contamination in feed ranged from $0.5-20 \mathrm{mg} / \mathrm{kg}$ for a variable time interval $[7,26,27]$.

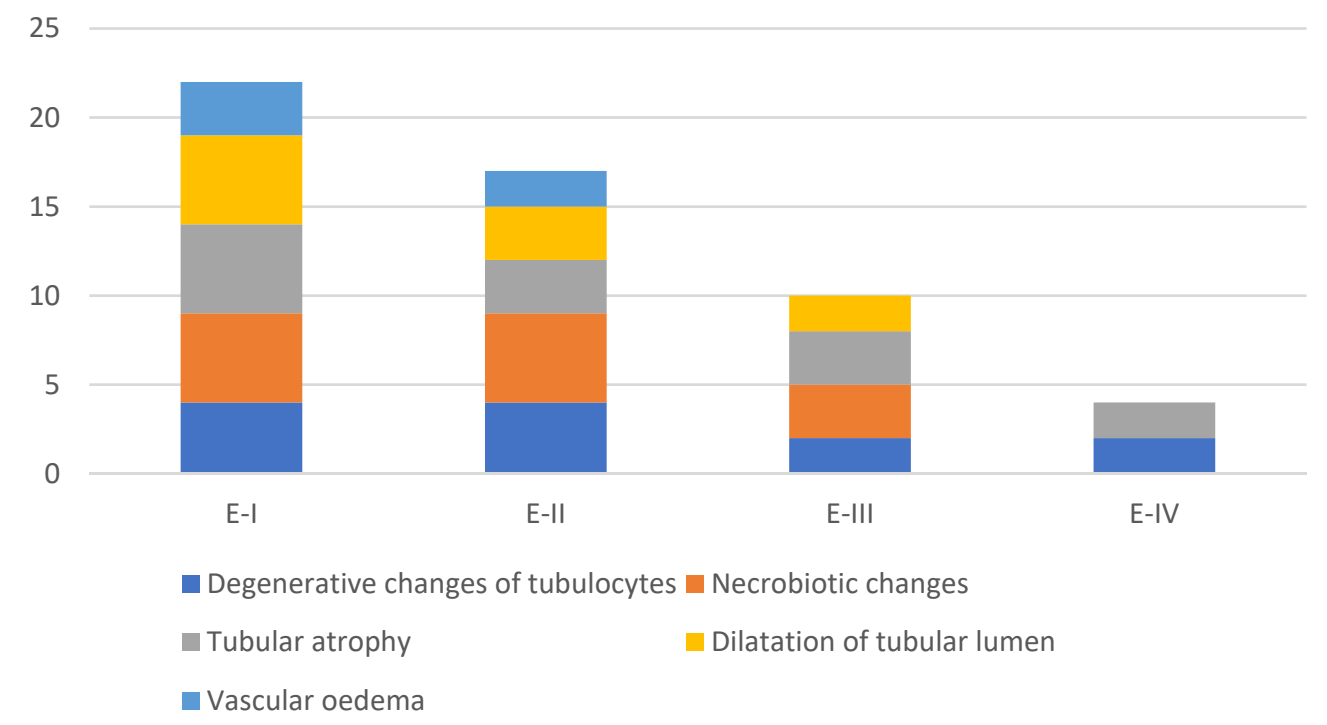

Figure 4. Incidence of histopathological changes on the kidneys. 


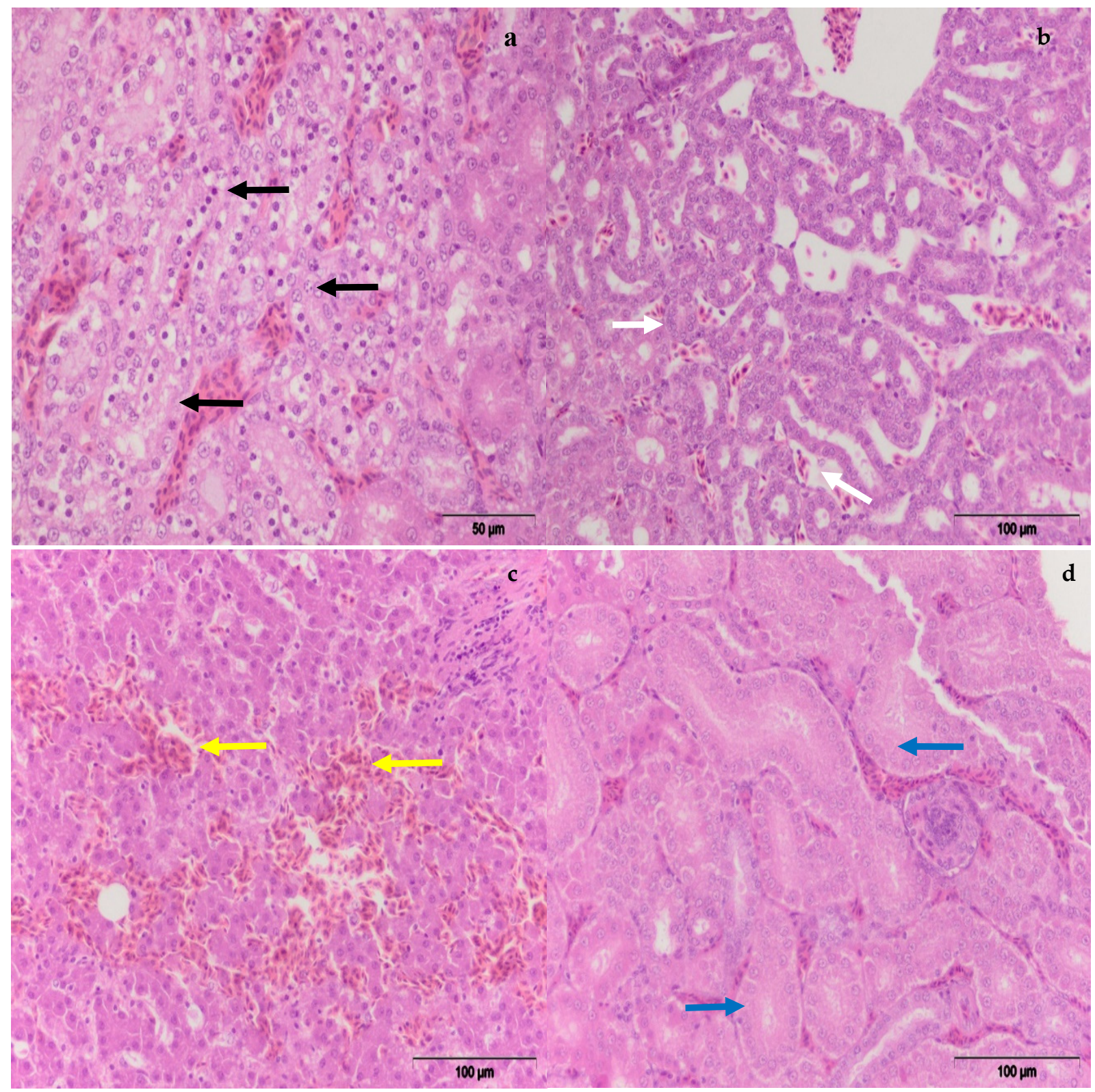

Figure 5. (a) Necrobiotic changes (karyopyknosis, karyorrhexis, karyolysis) (black arrows), E-I group; (b) tubular atrophy, E-I group (white arrows); (c) hemorrhagic areas with massive effusion of red blood cells (yellow arrows), E-I group; (d) degenerative changes of tubulocytes (cloudy and hydropic degeneration) E-III group (blue arrows). 

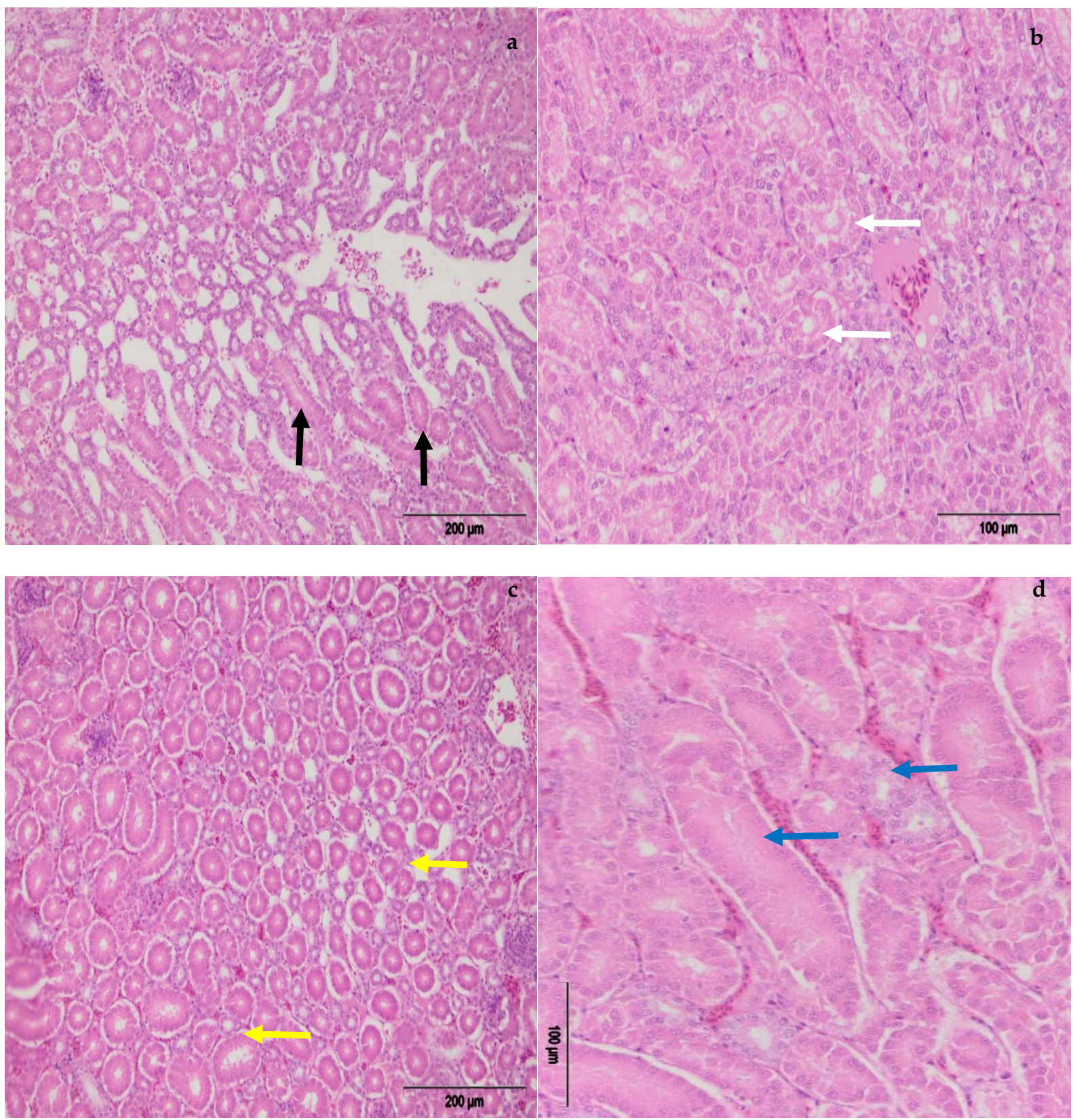

Figure 6. (a) Tubular atrophy, E-II group (black arrows); (b) degenerative changes of tubulocytes (cloudy and hydropic degeneration) E-II group (white arrows); (c) tubular atrophy, E-IV group (yellow arrows); (d) degenerative changes of tubulocytes, E-IV group blue arrows).

The incidence and severity of histopathological changes in the liver are presented in Figures 7 and 8. A similar pattern was observed in the liver. Histopathological examination of the liver showed degenerative changes (cloudy swelling, vacuolar degeneration, fatty change), focal necrosis of hepatocytes, and the activation of endothelial and Kupffer's cells, mainly present in the hens treated with different amounts of OTA. Similarly to in the kidney, the changes were less pronounced in the hens which, in addition to OTA in feed, received the adsorbent, $\mathrm{MZ}$. 


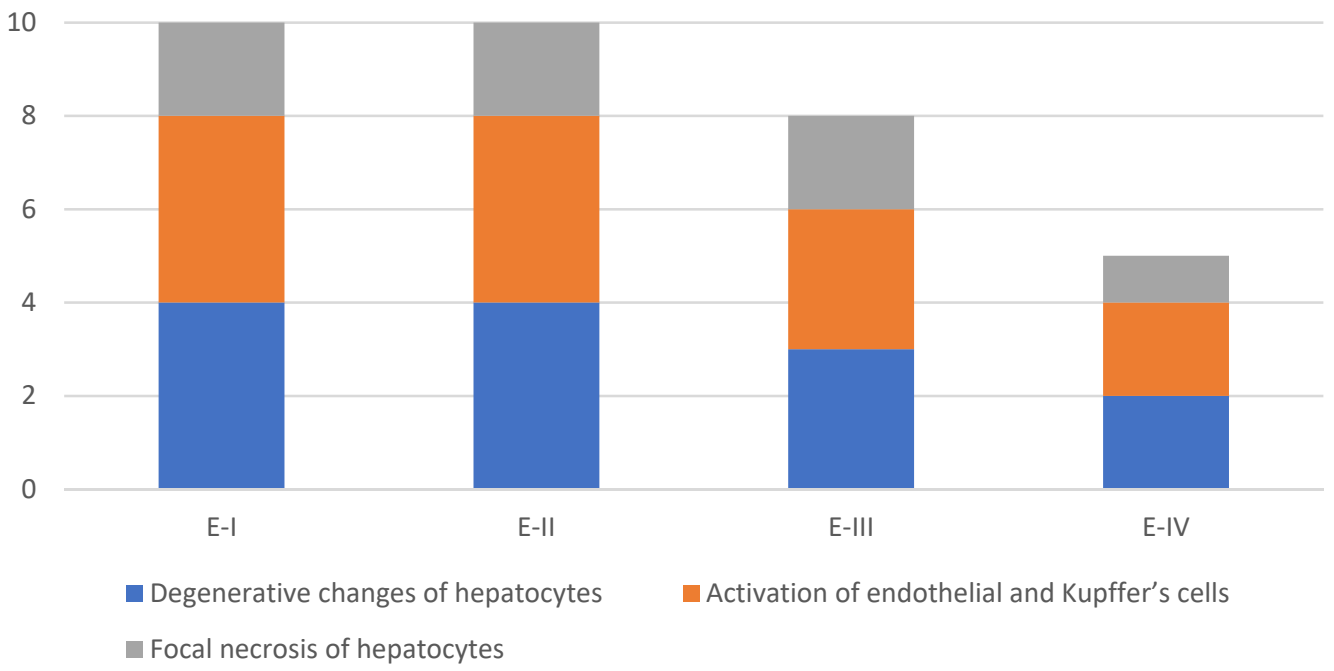

Figure 7. Incidence of histopathological changes in the liver.

Histopathological changes in the kidneys and liver of hens from different experimental groups were in the form of degenerative and necrotic alterations. The examination of kidneys revealed a pattern suggestive of a tubulonephrotic change (cloudy and hydropic degeneration, together with necrobiotic changes; karyopyknosis, karyorrhexis, karyolysis). Beside these changes, tubular atrophy and cystic dilatation of the tubular lumen and vascular changes (vascular edema) were also present. Histopathological examination of the liver tissue also showed degenerative and necrotic changes (cloudy swelling, vacuolar degeneration, fatty change, focal necrosis of hepatocytes, and the activation of endothelial and Kupffer's cells). All of these pathologic changes observed in the kidneys and liver can be explained by the route of elimination of OTA through the kidneys, and partly through the liver, because of enterophepatic recirculation of this mycotoxin through hepatobiliary excretion. These changes, observed both in the kidneys and liver, were mainly observed in the hens treated only with OTA. On the other hand, the less pronounced changes in the hens that were given the adsorbent can be explained by the protective effect of the adsorbent MZ [19,28-33]. It is obvious that the protective effect of the adsorbent MZ depends on the concentration of OTA in the feed. This finding indicates that a dose-dependent study of the protective effects of the adsorbent MZ on different concentrations of OTA in feed should also be performed.

\subsection{Residue of OTA in Eggs}

Exposure Assessment and Risk Characterization

Besides the effects on animal health, OTA has the potential to bioaccumulate in the edible tissues of food producing animals, causing food safety issues and posing a hazard to human health. Carry-over studies and surveys of OTA residues in eggs in Serbia have not been extensively carried out. Risk assessment is the systematic characterization of potential adverse effects on humans caused by exposure to hazardous agents. The results of dietary adsorbent MZ on concentrations of OTA residue in eggs and data about the hypothetical daily intake of OTA by consuming contaminated eggs are shown in Table 1. 

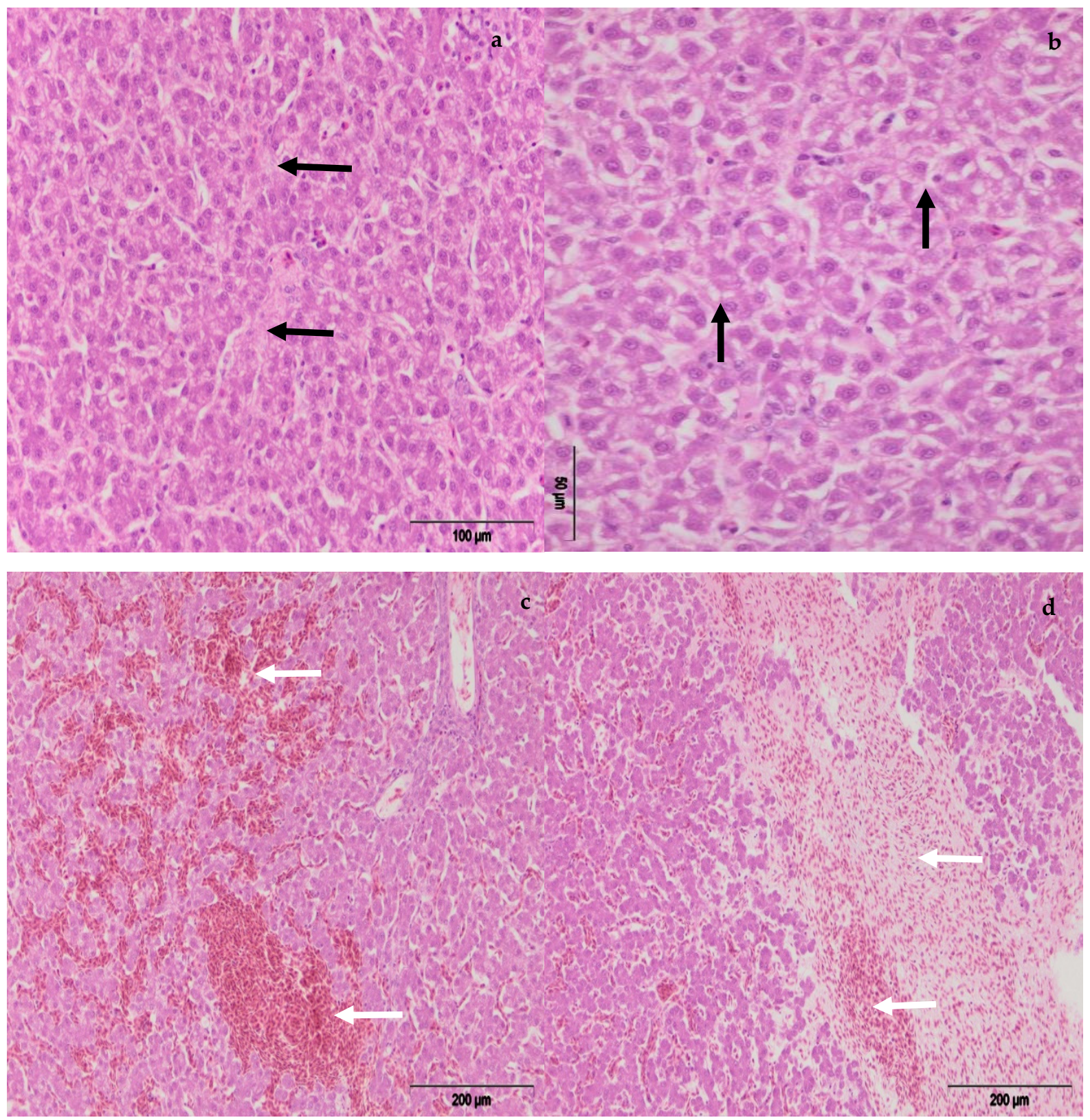

Figure 8. Degenerative changes (vacuolar degeneration, fatty change) of hepatocytes, (a) E-I group; (b) E-II group (black arrows); liver with hyperemia and hemorrhage, (c) E-III group, (d) E-IV group (white arrows).

It was assumed that both contamination scenarios could occur in reality (E-I and E-II), including the worst-case. Hence, the experiment was performed to determine the protective effects of using adsorbent MZ on different concentrations of OTA residues in eggs. Significant amounts of OTA were detected in the eggs of birds fed with $1 \mathrm{mg} / \mathrm{kg}$ OTA (E-I), reaching maximum levels of $0.377 \mu \mathrm{g} / \mathrm{kg}$ (day 49); while supplementing the contaminated diet with adsorbent MZ (1 mg/kg OTA $+0.2 \% \mathrm{MZ})$ significantly reduced the residue of OTA in eggs (up to $36.4 \%$ ). From the above data the carry over rate of OTA was shown to vary between 0.017 and $0.037 \%$. The reason for the maximum level of OTA residue in eggs being on 49 day, presumably lies in the enterohepatic recycling of OTA and consequently its slow elimination [28]. There is a correlation between OTA concentration in feed, duration of intake, and its residues in eggs $(r=0.913, p<0,05)$. We did not observe OTA residues in the eggs of laying hens fed diets containing $0.25 \mathrm{mg} / \mathrm{kg}$ OTA, which confirms the safety of the feed for laying hens from a regulatory point of 
view. In the avian species, the presence of OTA in eggs has been reported by several authors. Bauer et al. [34] measured OTA concentrations of $0.1-0.2 \mu \mathrm{g} / \mathrm{kg}$ in egg white and of $1.6-4 \mu \mathrm{g} / \mathrm{kg}$ in yolk following the administration of OTA to laying hens at dietary levels of 1.3, 2.6, and $5.2 \mathrm{mg} / \mathrm{kg}$ in feed. However, Krogh [35] reported no detection of OTA in eggs of laying hens fed diets containing 0.3 and $1 \mathrm{mg}$ of OTA $/ \mathrm{kg}$ feed. In contrast, OTA was detected in the eggs of hens fed a higher dosage $(10 \mathrm{mg} / \mathrm{kg}$ feed) of the toxin [36]. The differences between studies may have been due to the different study settings and methods that were used, and these do not allow for an easy comparison of results.

Table 1. Effects of dietary adsorbent MZ on concentrations of OTA residue in eggs, and EDI of OTA by consuming contaminated eggs.

\begin{tabular}{|c|c|c|c|c|c|}
\hline \multicolumn{6}{|c|}{ Treatment Group } \\
\hline \multirow{6}{*}{$\begin{array}{l}\text { OTA residue in eggs } \\
\qquad(\mu \mathrm{g} / \mathrm{kg})\end{array}$} & Days & E-I & E-II & E-III & E-IV \\
\hline & 7 & $0.173 \pm 0.00$ & \multirow{5}{*}{ ND } & $0.063 \pm 0.00$ & \multirow{5}{*}{ ND } \\
\hline & 14 & $0.157 \pm 0.00$ & & $0.070 \pm 0.00$ & \\
\hline & 21 & $0.223 \pm 0.02$ & & $0.079 \pm 0.00$ & \\
\hline & 42 & $0.333 \pm 0.01$ & & $0.084 \pm 0.00$ & \\
\hline & 49 & $0.377 \pm 0.02$ & & $0.088 \pm 0.00$ & \\
\hline \multirow{5}{*}{$\begin{array}{c}\text { EDI } \\
\text { (ng/kg bw/day) }\end{array}$} & 7 & 0.090 & \multirow{5}{*}{ ND } & 0.033 & \multirow{5}{*}{ ND } \\
\hline & 14 & 0.082 & & 0.036 & \\
\hline & 21 & 0.116 & & 0.041 & \\
\hline & 42 & 0.173 & & 0.044 & \\
\hline & 49 & 0.196 & & 0.046 & \\
\hline
\end{tabular}

Based on the concentrations of OTA determined in egg samples, we roughly estimated the hypothetical dietary intake (EDI) of OTA. For each combination of contamination scenarios, the EDI was calculated. On day 49 of the study, the DI values for the adult population were estimated as $0.195 \mathrm{ng} / \mathrm{kgbw} /$ day, for the group that received $1 \mathrm{mg} / \mathrm{kg}$ OTA in feed. While, in the second scenario where $\mathrm{MZ}$ was added $(1 \mathrm{mg} / \mathrm{kg}$ OTA $+0.2 \% \mathrm{MZ})$ added, the EDI was significantly lower (maximum $0.046 \mathrm{ng} / \mathrm{kg} \mathrm{w} /$ day). In our study, the calculated EDI and TWI was significantly lower than the tolerable weekly intake proposed by the EFSA (120 ng/kg b.w./week) [37]. Overall, our findings suggest that the public health concern for consuming eggs from these laying hens is negligible. Hence, to ensure the safety of eggs for human consumption, it is extremely important to monitor stored feed in order to provide feed in accordance with the maximum permitted level of OTA in feed for poultry $[18,19]$. Furthermore, this model can help food safety authorities and feed business operators to better allocate resources for food safety monitoring throughout the food chain.

\section{Conclusions}

The results of a longitudinal study showed that OTA at levels of $1 \mathrm{mg} / \mathrm{kg}$ OTA in feed for 7-49 days adversely affected the production performance and resulted in histopathological disturbances to the kidneys and liver of laying hens. Based on these results, the OTA expressed a more or less a negative impact on body weight and feed consumption in both applied concentrations. On the other hand, modified clinoptilolite (MZ) supplementation in poultry feed at the level $0.2 \%$ led to a significant reduction in the harmful effects of OTA, on the macroscopic and pathomorphological alterations in target organs, and on production parameters in laying hens. Considering the current risk assessment, the calculated EDI and TWI was significantly lower than the tolerable weekly intake proposed by the EFSA (120 ng/kg b.w./week). Overall, our findings suggest that with this negligible rate of carry-over, no obvious health risks were observed for intake of OTA from egg consumption at the tested concentrations. Despite the low concern, our results indicate a need for continuous monitoring of OTA in feed and a further evaluation 
of health effects in farm animals in order to avoid or reduce the presence of this natural contaminant in the entire food chain.

\section{Materials and Methods}

\subsection{Birds and Diets}

Forty eight $(n=48)$ laying Lowman Brown hens (27-week-old) were used in this study. The average body weight of birds was $1520 \pm 87.29 \mathrm{~g}$, while the study lasted 49 days. At the beginning of the experiment, the number of eggs per housed hen per day was averaged at $0.93 \pm 0.3$. Birds were placed in a light-controlled (16 h Light: $8 \mathrm{~h}$ Dark) and temperature-controlled $\left(22^{\circ} \mathrm{C}\right)$ room in wire cages with unlimited access to drinking water.

The OTA-challenge diets were artificially contaminated using OTA produced in vitro by contamination of corn with Aspergillus ochraceus Wilhelm NRRL 263.67 culture. Conidospores of $A$. ochraceus were cultivated on potato dextrose-agar substrates for five days at $27^{\circ} \mathrm{C}$, followed by corn contamination with the obtained cultures. The corn with cultures of A. ochraceus was kept at a temperature of $15-25{ }^{\circ} \mathrm{C}$ during contamination. After 10 days, the corn was dried at $105^{\circ} \mathrm{C}$ in a laboratory drying cabinet in order to destroy the mold. The amount of OTA in the ground medium was quantified by LC/MS/MS on the certified standard blank corn. Results showed that the medium contained $270 \mathrm{mg} / \mathrm{kg}$ OTA. All other mycotoxins were under the detection limit. After homogenization, the ground medium was mixed into the commercial mixture for laying hens, with $15 \%$ of raw proteins. Hens were equally divided into six groups and, depending on the type of addition, were allocated to the following experimental treatments for 7 weeks: E-I group $-1 \mathrm{mg} / \mathrm{kg}$ OTA; E-II group $0.25 \mathrm{mg} / \mathrm{kg}$ OTA; E-III group $1 \mathrm{mg} / \mathrm{kg}$ OTA $+0.2 \%$ of MZ; E-IV group $0.25 \mathrm{mg} / \mathrm{kg}$ OTA $+0.2 \%$ of MZ, MZ group of hens was fed with standard diets in addition to only $0.2 \%$ of the adsorbent. The control group (C) of hens was fed only a standard diet, without any addition. After mixing the feed, samples were taken in order to determine the level of OTA in the animal feed using the UPLC MS/MS technique. The average concentration of OTA in the feed of the EI group was $1.025 \mathrm{mg} / \mathrm{kg}$, E-II $0.248 \mathrm{mg} / \mathrm{kg}$, E-III $1.011 \mathrm{mg} / \mathrm{kg}$, and E IV $-0.251 \mathrm{mg} / \mathrm{kg}$.

Hens were fed once a day, while the standard diet consisted of complete mixtures (with or without the additions above), whose raw and chemical composition was according to the NRC recommendations [38]. This particular adsorbent, which was chosen for its domestic origin, was obtained from the producer for solely scientific purposes.

All procedures were done in accordance with a permit from the Ethics Committee of the Ministry of Agriculture, Forestry, and Water Management, as well as the Veterinary Directorate Republic of Serbia no 323-07-00241/2019-05-01.

\subsection{Hen Production Performance}

Eggs were collected daily to investigate the number of eggs, and the feed consumption was measured daily. On the other hand, body weights were recorded weekly.

\subsection{Histopathological Examinations of Livers and Kidneys}

The samples for histopathological examination were fixed in a solution of $10 \%$ neutral formalin and absolute ethanol and were molded by the standard paraffin technique. Tissue samples $(5-8 \mu \mathrm{m})$ were then stained by the hematoxylin eosin technique, as described by Scheuder and Chalk [39].

\subsection{Analysis of Mycotoxins}

Before artificial contamination with OTA, the feed was tested for the presence of other mycotoxins (aflatoxin B1, deoxynivalenol, trichothecenes, fumonisins, and zearalenone) in order to avoid synergistic toxic effects on broilers. Analyses of mycotoxins were carried out for OTA as previously published by Nedeljković-Trailović et al. [14]. 


\subsection{Residues of OTA in Eggs}

Since the OTA levels in eggs were expected to be in the sub-ppb range, a sensitive method for the quantitative determination had to be employed. A QuEChERS-based technique for extraction and clean-up was combined with a highly selective LC-MS/MS analysis to achieve accurate and reliable results.

Analytical standard OTA was purchased from Sigma-Aldrich (St.Louis, MO, USA). Stock solution was prepared in acetonitrile and stored at $-20^{\circ} \mathrm{C}$. Acetic and formic acid were obtained from Merck (Darmstadt, Germany). HPLC-grade water, methanol, and acetonitrile were purchased from Sigma-Aldrich. The working standard solution was prepared in acetonitrile by diluting stock solution and stored at $4{ }^{\circ} \mathrm{C}$.

Samples were analyzed with the LC-MS/MS system manufactured by Agilent (Santa Clara, CA, USA), consisting of an Agilent 1290 Infinity II pump, autosampler, and Agilent 6420 Triple quad. The analytical column used for separation was an Agilent Polaris 5, $\mathrm{C} 1850 \times 2 \mathrm{~mm}$, and $5 \mu \mathrm{m}$ particle size. Column oven temperature was set at $45^{\circ} \mathrm{C}$. The chromatographic separation was achieved in gradient mode, using water acidified with $0.1 \%$ formic acid (mobile phase A) and methanol acidified with $0.1 \%$ formic acid (mobile phase B) at a flow rate of $0.35 \mathrm{~mL} / \mathrm{min}$. Gradient elution was applied to efficiently separate OTA from matrix interferences. Separation started at 100\% A, reaching $100 \% \mathrm{~B}$ in $2 \mathrm{~min}$, and maintaining that composition for another $2 \mathrm{~min}$, followed by three minutes re-equilibration. Total analysis time was 7 min per sample. Electrospray ionization (ESI+) was used, with the following parameters: capillary voltage $4 \mathrm{kV}$, nebulizer gas $\left(\mathrm{N}_{2}\right)$ pressure was set to $0.35 \mathrm{MPa}$. Nitrogen was used as a collision gas. The precursor and product ions for OTA were $404>239$ and $404>221$, collision energy was $19 \mathrm{~V}$ for both transitions, fragment was set to $60 \mathrm{~V}$ and cell acceleration voltage to $4 \mathrm{~V}$.

The sample preparation method was modified from the procedure described in the paper presented by Garrido Frenich et al. [40]. Briefly, $5 \mathrm{~g}$ of sample, previously homogenized on a Ultra thurrax IKA Yellow line (IKA, Werke, Germany), was weighted into the polypropylene centrifuge tube and $20 \mathrm{~mL}$ of methanol/water solution $(80 / 20 \mathrm{v} / \mathrm{v})$ acidified with $1 \%$ acetic acid was added, together with $8 \mathrm{~g}$ of sodium acetate anhydrous. This mixture was vortexed for $2 \mathrm{~min}$, followed by shaking in a horizontal IKA Yellow line shaker for $15 \mathrm{~min}$. Tubes were then centrifuged for $5 \mathrm{~min}$ at $3500 \times \mathrm{g}$ in a Sigma 2-16P centrifuge (37520 Osterode am Harz, Germany). The cleanup step was performed by passing the previously filtered supernatant through nylon syringe filters $(0.45 \mu \mathrm{m}$ pore size $)$ and through a Waters (Milford, MA, USA) Oasis HLB cartridge. To achieve an increased sensitivity, the purified extract was concentrated under a gentle stream of nitrogen at $50{ }^{\circ} \mathrm{C}$ to $0.5 \mathrm{~mL}$ and transferred to a HPLC vial for analysis.

The analytical method was validated before the analysis of the samples using blank egg samples, previously determined to be free from OTA, and fortified at various levels. The validation parameters assessed were linearity, limit of quantification, accuracy (expressed as recovery percentage), and precision (expressed as relative standard deviation; RSDr of interlaboratory reproducibility). Validation levels were from 0.1 to $5 \mu \mathrm{g} / \mathrm{kg}$, the determined LoQ was $0.05 \mu \mathrm{g} / \mathrm{kg}$, and the average recovery was from $45 \%$ at $0.1 \mu \mathrm{g} / \mathrm{kg}$ to $106 \%$ at $5 \mu \mathrm{g} / \mathrm{kg}$ while RSDr at $0.1 \mu \mathrm{g} / \mathrm{kg}$ was $37 \%$. Excellent linearity was observed with an average $R^{2}$ of 0.998 .

\subsection{Calculation of the Human Estimated Daily Intake}

In this study a simplified, hypothetical estimation of human daily intake (EDI) of OTA by consuming eggs contaminated with OTA was used. The daily intake was assessed for different contamination scenarios (different concentrations and durations), combining contamination data from the trial $\left(\Sigma \mathrm{c}, \mu \mathrm{g} \mathrm{kg}{ }^{-1}\right)$ with national consumption data $(\mathrm{C}, \mathrm{kg})$ and body weight $(\mathrm{K})$ for each consumer according to the following formula [41]:

$$
\mathrm{EDI}=\left(\Sigma_{\mathrm{c}}\right) \times \mathrm{C} / \mathrm{K}
$$


The latest assessment of the mean daily intake of eggs is 0.61 pieces / per capita (36.4 g). Mean body weight for the adult Serbian population is considered $70 \mathrm{~kg}$ [42]. The individual exposure to OTA was compared with the tolerable weekly intake (TWI) value established by the EFSA (37) (120 ng/kg b.w./week).

\subsection{Statistical Analysis}

All results were statistically analyzed for differences between groups, by an analysis of variance (ANOVA). The results were processed using Graph Pad Prism ${ }^{\circledR} 5.0$ software (Graph Pad Software Inc., San Diego, CA, USA). All values are expressed as the mean $\pm \mathrm{SE}$.

Author Contributions: Conceptualization, J.N.T.; methodology, D.M. (Darko Marinković), J.P., S.S., J.R.; formal analysis, D.M. (Darko Marinković); S.S.; J.R.; resources, M.V.; data curation, B.P.; writingoriginal draft preparation, J.N.T. and D.M. (Dragan Milićević); writing-review and editing, D.M. (Dragan Milićević) and S.T.; visualization, D.M. (Darko Marinković) supervision, J.P. All authors have read and agreed to the published version of the manuscript.

Funding: This research was funded by the Ministry of Education, Science and Technological Development, Republic of Serbia, Grant No. TR 31087 and the contract number 451-03-68/2020-14/200143.

Institutional Review Board Statement: The protocol and procedure used in this study were reviewed and approved by the Ethics Committee of the Ministry of Agriculture, Forestry and Water Management as well as the Veterinary Directorate Republic of Serbia no 323-07-00241/2019-05-01, approved on 16 January 2019.

Informed Consent Statement: Informed consent was obtained from all subjects involved in the study.

Data Availability Statement: Not applicable.

Conflicts of Interest: The authors declare no conflict of interest.

\section{References}

1. Malir, F.; Ostry, V.; Pfohl-Leszkowicz, A.; Malir, J.; Toman, J. Ochratoxin A: 50 Years of research. Toxins 2016, 8, 191. [CrossRef] [PubMed]

2. Duarte, S.C.; Pena, A.; Lino, C.M. A review on ochratoxin A occurrence and effects of processing of cereal and cereal derived food products. Food Microbiol. 2010, 27, 187-198. [CrossRef] [PubMed]

3. International Agency for Cancer Research. Group 2B: Possibly Carcinogenic to Humans. Pages 245-395 in Monographs on the Evaluation of Carcinogenic Risks of Chemicals to Humans; International Agency for Cancer Research: Lyon, France, 1993 ; Volume 56.

4. Pleadin, J. Mycotoxins in grains and feed-contamination and toxic effect in animals. Biotechnol. Anim. Husb. 2015, 31, 441-456. [CrossRef]

5. Yang, C.; Song, G.; Lim, W. Effects of mycotoxin-contaminated feed on farm animals. J. Hazard. Mater. 2020, $389,122087$. [CrossRef] [PubMed]

6. Vila-Donat, P.; Marín, S.; Sanchis, V.; Ramos, A.J. A review of the mycotoxin adsorbing agents, with an emphasis on their multi-binding capacity, for animal feed decontamination. Food Chem. Toxicol. 2018, 114, 246-259. [CrossRef] [PubMed]

7. Milicevic, D.; Jovanovic, M.; Matekalo-Sverak, V.; Radicevic, T.; Petrovic, M.M.; Lilic, S. A Survey of Spontaneous Occurrence of Ochratoxin A Residues in Chicken Tissues and Concurrence With Histopathological Changes in Liver and Kidneys. J. Environ. Sci. Health C Environ. Carcinog. Ecotoxicol. Rev. 2011, 29, 159-175. [CrossRef]

8. Wang, L.; Zhang, Q.; Yan, Z.; Tan, Y.; Zhu, R.; Yu, D.; Yang, H.; Wu, A. Occurrence and Quantitative Risk Assessment of Twelve Mycotoxins in Eggs and Chicken Tissues in China. Toxins 2018, 10, 477. [CrossRef]

9. Milićević, D.; Jovanović, M.; Matekalo-Sverak, V.; Radičević, T.; Petrović, M.M.; Vuković, Ž.D. Residue of ochratoxin A in chicken tissues-risk assessment. Arch. Oncol. 2011, 19, 23-27. [CrossRef]

10. Kos, J.; Janić Hajnal, E.; Malachová, A.; Steiner, D.; Stranska, M.; Krska, R.; Poschmaier, B.; Sulyok, M. Mycotoxins in maize harvested in Republic of Serbia in the period 2012-2015. Part 1: Regulated mycotoxins and its derivatives. Food Chem. 2020, 312, 126034. [CrossRef]

11. Udovicki, B.; Audenaert, K.; De Saeger, S.; Rajkovic, A. Overview on the Mycotoxins Incidence in Serbia in the Period 2004-2016. Toxins 2018, 10, 279. [CrossRef]

12. Milićević, D.; Udovički, B.; Petrović, Z.; Janković, S.; Radulović, S.; Gurinović, M.; Rajković, A. Current status of mycotoxin contamination of food and feeds and associated public health risk in Serbia. Meat Technol. 2020, 61, 1-36. [CrossRef]

13. Karovic, D.; Djermanovic, V.; Mitrovic, S.; Radovic, V.; Okanovic, D.; Filipovic, S.; Djekic, V. The effect of mineral adsorbents in poultry production. Worlds Poult. Sci. J. 2013, 69, 335-342. [CrossRef] 
14. Nedeljković-Trailović, J.; Trailović, S.; Resanović, R.; Milićević, D.; Jovanovic, M.; Vasiljevic, M. Comparative Investigation of the Efficacy of Three Different Adsorbents against OTA-Induced Toxicity in Broiler Chickens. Toxins 2015, 7, 1174-1191. [CrossRef]

15. Elaroussi, M.A.; Mohamed, F.R.; EL Barkouky, E.M.; Atta, A.M.; Abdou, A.M.; Hatab, M.H. Experimental ochratoxicosis in broiler chickens. Avian Pathol. 2006, 35, 263-269. [CrossRef] [PubMed]

16. Denli, M.; Blandon, J.C.; Guynot, M.E.; Salado, S.; Perez, J.F. Efficacy of a New Ochratoxin-Binding Agent (OcraTox) to Couteract the Deleterious Effects of Ochratoxin A in Laying Hens. Poult. Sci. 2008, 87, 2266-2272. [CrossRef] [PubMed]

17. Pietro, C.L.C.; Aaron, F.; Fru-Nji, E.S.; Robert, K. Anna-Maria, and V. Viviane. Gastrointestinal functionality in animal nutrition and health: New opportunities for sustainable animal production. Anim. Feed Sci. Tech. 2017, 234, 88-100.

18. Regulation, S. Maximum allowed contents of contaminants in food and feed. Off. Bull. Repub. Serb. 2011, 28, 1-6.

19. European Commission (EC). Commission Recommendation 576/2006/EC of 17 August 2006 on the presence of deoxynivalenol, zearalenone, ochratoxin A, T-2 and HT-2 and fumonisins in products intended for animal feeding. Off. J. Eur. Union 2006, L229, 7.

20. Raj, J.; Vasiljević, M.; Tassis, P.; Farkaš, H.; Bošnjak-Neumüller, J.; Männer, K. Effects of a modified clinoptilolite zeolite on growth performance, health status and detoxification of aflatoxin B1 and ochratoxin A in male broiler chickens. Br. Poult. Sci. 2021, 12, 1-10. [CrossRef]

21. Shuangshuang, Z.; Yongwen, Z.; Peishi, F.; Macheng, L.; Wence, W.; Lin, Y.; Ye, Y. Ochratoxin A: Its impact on poultry gut health and microbiota, an Overview. Poult. Sci. 2021, 100, 101037. [CrossRef]

22. Sakthivelan, S.M.; Rao, G.V.S. Effect of ochratoxin A on body weight, feed intake and feed conversion in broiler chicken. Vet. Med. Int. 2010, 2010, 590432. [CrossRef]

23. Dakovic, A.; Matijaševic, S.; Rottinghaus, G.E.; Dondur, V.; Pietrass, T.; Clewett, C.F.M. Adsorption of zearalenone by organomodified natural zeolitic tuff. J. Colloid Interface Sci. 2007, 311, 8-13. [CrossRef] [PubMed]

24. Vujakovic, A.D.; Tomasevic-Canovic, M.R.; Dakovic, A.S.; Dondur, V.T. The adsorption of sulphate, hydrogenchromate and dihydrogenphosphate anions on surfactant-modified Clinoptilolite. Appl. Clay Sci. 2000, 17, 265-277. [CrossRef]

25. Stoev, D.S. Foodborne mycotoxicoses, risk assessment and underestimated hazard of masked mycotoxins and joint mycotoxin effects or interaction. Environ. Toxicol. Pharmacol. 2015, 39, 794-809. [CrossRef] [PubMed]

26. Kumar, A.; Jindal, N.; Shukla, C.L.; Asrani, R.K.; Ledoux, D.R.; Rottinghaus, G.E. Pathological changes in broiler chickens fed ochratoxin A and inoculated with Escherichia coli. Avian Pathol. 2004, 33, 413-417. [CrossRef] [PubMed]

27. Abidin, Z.; Khan, M.Z.; Khatoon, A.; Saleemi, M.K.; Khan, A. Protective effects of lcarnitine upon toxicopathological alterations induced by ochratoxin A in white Leghorn cockerels. Toxin Rev. 2016, 35, 157-164. [CrossRef]

28. Fuchs, R.; Appelgren, L.E.; Hagelberg, S.; Hult, K. Carbon-14-ochratoxin A distribution in the Japanese quail (Coturnixcoturnix japonica) monitored by whole-body autography. Poult Sci. 1988, 67, 707-714. [CrossRef]

29. Roth, A.; Chakor, K.; Ekuecreepy, E.; Kane, A.; Roschenthaler, R.; Dirheimer, G. Evidence for an enterohepatic circulation of ochratoxin A in mice. Toxicology 1988, 48, 293-308. [CrossRef]

30. Dwivedi, P.; Burns, R.B. Pathology of ochratoxicosis in young broilerchicks. Res. Vet. Sci. 1984, 36, 92-103. [CrossRef]

31. Stoev, S.D.; Djuvinov, D.; Mirtcheva, T.; Pavlov, D.; Mantle, P. Studies on some feed additives giving partial protection against ochratoxin A toxicity in chicks. Toxicol. Lett. 2002, 135, 33-50. [CrossRef]

32. Bozzo, G.; Bonerba, E.; Ceci, E.; Colao, V.; Tantillo, G. Determination of ochratoxin A in eggs and target tissues of experimentally drugged hens using HPLC-FLD. Food Chem. 2011, 126, 1278-1282.

33. Stoev, S.D. Studies on carcinogenic and toxic effects of ochratoxin A in chicks, Special issue "Ochratoxins". Toxins 2010, 2, 649-664. [CrossRef]

34. Bauer, J. Methods for detoxification of mycotoxins in feedstuffs. Monatsh. Veterinarmed. 1994, 49, $175-181$.

35. Krogh, P. Ochratoxin in food. In Mycotoxins in Food; Krogh, P., Ed.; Academic Press/Harcourt Brace Jovanovich: London, UK, 1987; pp. 97-122.

36. Piskorska-Pliszczyńka, J.; Juszkiewicz, T. Tissue deposition and passage into eggs of ochratoxin A in Japanese quail. J. Environ. Pathol. Toxicol. Oncol. 1990, 10, 8-10.

37. EFSA. Opinion of the Scientific Panel on Contaminants in the food Chain on a Request from the Commission Related to Ochratoxin A in Food. Efsa J. 2006, 365, 1-56.

38. NRC (National Research Council). Nutrient Requirements of Poultry; Ninth Revised, Ed.; National Academy Press: Washington, DC, USA, 1994.

39. Scheuer, P.J.; Chalk, B.T. Histopathology; Wolfe Medical Publications: London, UK, 1986.

40. Frenich, A.G.; Romero-González, R.; Gómez-Pérez, M.L.; Vidal, J.L.M. Multi-mycotoxin analysis in eggs using a QuEChERSbased extraction procedure and ultra-high-pressure liquid chromatography coupled to triple quadrupole mass spectrometry. $J$. Chromatogr. A 2011, 1218, 4349-4356. [CrossRef] [PubMed]

41. IPCS e International Programme on Chemical Safety. Dietary exposure assessment of chemicals in food. In Principles and Methods for the Risk Assessment of Chemicals in Food; WHO: Genève, Switzerland, 2009.

42. Scientifis opinion Guidance on selected default values to be used by the EFSA Scientific Committee, Scientific Panels and Units in the absence of actual measured data. EFSA J. 2012, 10, 2579. 